\title{
In vivo Studies of Methanogenesis in the Bovine Rumen: Dissimilation of Acetate
}

\author{
By R. A. OPPERMANN,* W. O. NELSON AND R. E. BROWN \\ Department of Dairy Science, University of Illinois, Urbana, Illinois, U.S.A.
}

(Received 1 November 1960)

\begin{abstract}
SUMMARY
The introduction of sodium acetate-2-14 $\mathrm{C}$ into a bovine rumen resulted in the in vivo labelling of the rumen gases and volatile fatty acids. The relative isotope concentration in substrate and products indicated that a maximum of $5.6 \%$ of the methane and $11 \%$ of the carbon dioxide in rumen gas might have been derived from the methyl carbon of acetate when the substrate was added to the rumen $18 \mathrm{hr}$. after the animal had been fed a normal ration. A maximum of $3 \cdot 2 \%$ of the methane and $4.2 \%$ of the carbon dioxide might have been derived from the methyl carbon of sodium acetate-2-14 $\mathrm{C}$ when this substrate was introduced into the rumen immediately after the animal had been fed. The addition of sodium acetate-1-14C to the rumen $18 \mathrm{hr}$. after feeding indicated that $2 \%$ of the methane and $10 \%$ of the carbon dioxide was derived from the carboxyl carbon of the substrate. Most of the derived radioactivity of the volatile acids of the rumen was found in the butyric acid fraction, although smaller amounts appeared in propionic acid and the volatile fatty acids with a chain length of greater than 4 carbons.
\end{abstract}

\section{INTRODUCTION}

The biochemical reactions mediated by the known species of methane bacteria (Barker, 1956) and the abundance of various methanogenic substrates in rumen fluid suggest that several pathways may be involved in rumen methane formation, as illustrated in Fig. 1. Beijer (1952) detected a Methanosarcina sp. in the goat rumen, and Oppermann, Nelson \& Brown (1957) demonstrated Methanobacterium formicicum and a methanogenic acetate-utilizer biochemically resembling Methanobacterium söhngenii in enrichment cultures from cattle rumen contents. Nelson, Oppermann \& Brown (1958) reported that rumen enrichment cultures stabilized to valeric or butyric acid contained methane bacteria which biochemically resembled Methanobacterium suboxydans. Smith \& Hungate (1958) isolated and characterized a new species Methanobacterium ruminantium which is present in the bovine rumen in great abundance. Thus, with the exception of the oxidation of propionic acid, there is evidence that the rumen contains bacteria capable of generating methane by the pathways shown in Fig. 1. The numerous unsuccessful attempts to obtain the utilization of propionic acid by rumen enrichment cultures (Oppermann et al. 1957; Nelson et al. 1958) are consistent with the observations of McNeill \& Brown (1954), and strongly suggest that propionate is not a substrate for rumen methanogenesis.

\footnotetext{
* Present address : Nalco Chemical Co., Chicago, Mlinois, U.S.A.
} 


\section{R. A. Oppermann, W. O. Nelson and R. E. Brown}

The abundance of evidence relative to the in vitro reduction of carbon dioxide to methane by rumen organisms (Carroll \& Hungate, 1955; Smith \& Hungate, 1958) and the efficiency of the in vivo reduction of carbon dioxide to methane by the rumen microflora (Kleiber, 1953) support the hypothesis that hydrogen and carbon dioxide are the chief substrates which give rise to methane in the rumen. However, the existence of acetate-utilizing methane bacteria in the rumen (Beijer, 1952; Oppermann et al. 1957; Nelson et al. 1958; Yahiro, 1959) suggests that some methane may arise from this source as it does in the anaerobic fermentation of certain industrial wastes (Buswell, 1936). The present investigation was conducted to measure the extent of the in vivo conversion of acetate to methane in the bovine rumen.

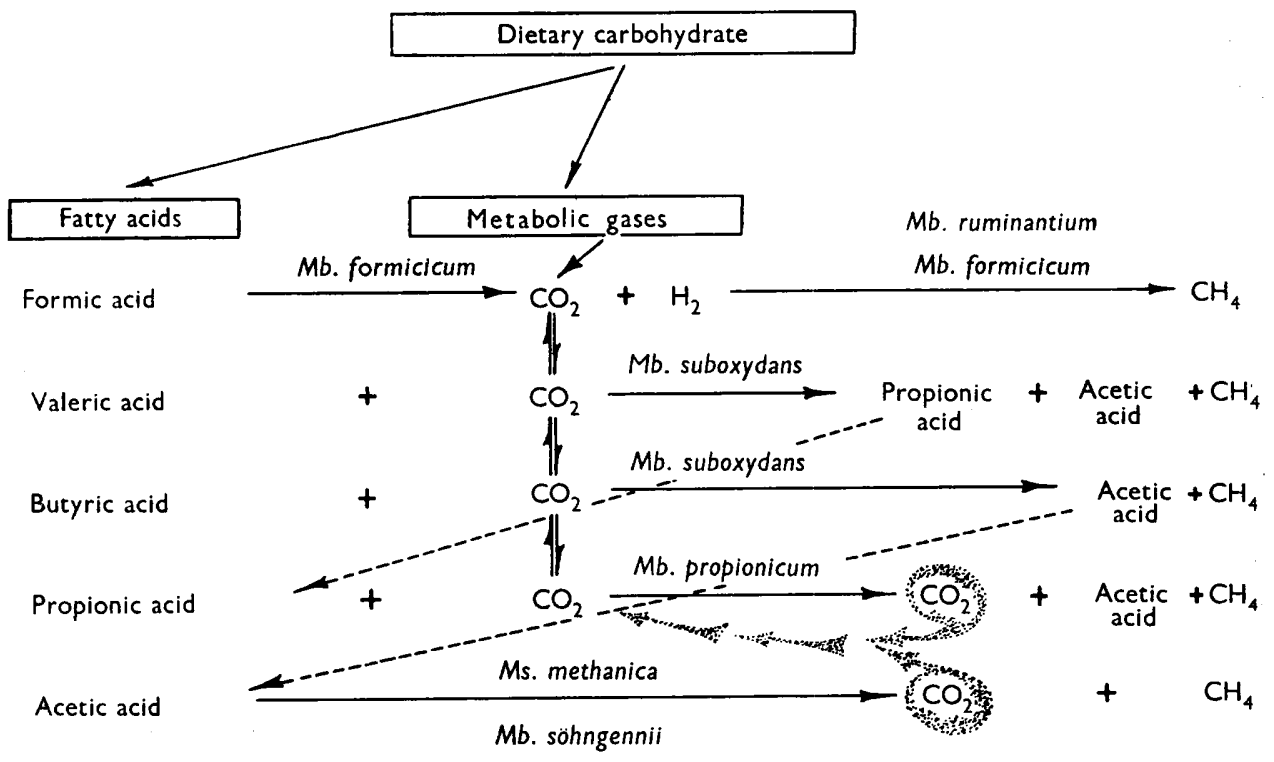

Fig. 1. Theoretical pathways of rumen methanogenesis.

\section{METHODS}

In vivo methods. The dissimilation of acetic acid with concomitant methanogenesis was studied in a rumen-fistulated dairy cow maintained on a daily intake of 24 $\mathrm{lb}$. of alfalfa hay and $5 \mathrm{lb}$. of a $14 \%$ protein concentrate mix. The apparatus used for the collection of rumen fluid and gas samples is schematically represented in Fig. 2. Samples of the rumen gas were forced into the Douglas bag by normal rumen contractions. Liquid samples were obtained by use of a sidearm test tube and an aspirator bulb.

The radioactive substrate was added to the rumen $18 \mathrm{hr}$. after the animal had been fed the standard roughage + concentrate ration, except in one trial as will be noted. This period in the rumen digestion cycle was postulated to be the most favourable for acetate utilization because: $(a)$ the approximate $1: 1$ ratio of carbon dioxide to methane found at this period (Nelson, Brown \& Kingwill, 1960) approaches the actual (Oppermann et al. 1957) and theoretical (Buswell, 1936) composition of gas obtained from the methanogenic dissimilation of acetate; $(b)$ the 
acetate concentration in rumen fluid is relatively constant at this period (Brown, 1954); (c) formate and carbon dioxide, which may be preferentially utilized and/or be inhibitory to acetate utilization (Oppermann et al. 1957), would be at negligible (formate) and minimum (carbon dioxide) concentrations.

Sodium acetate- ${ }^{14} \mathrm{C}$, labelled in either the 1 or 2 position, was dissolved in $500 \mathrm{ml}$. distilled water and added to the rumen through the fluid sampling line. The line then was flushed with from 1 to 1.51 . distilled water. An evacuated Douglas bag was connected to the gas-sampling line and the gas collected. At the end of each time period, the bag containing the sample was removed and an evacuated bag attached.

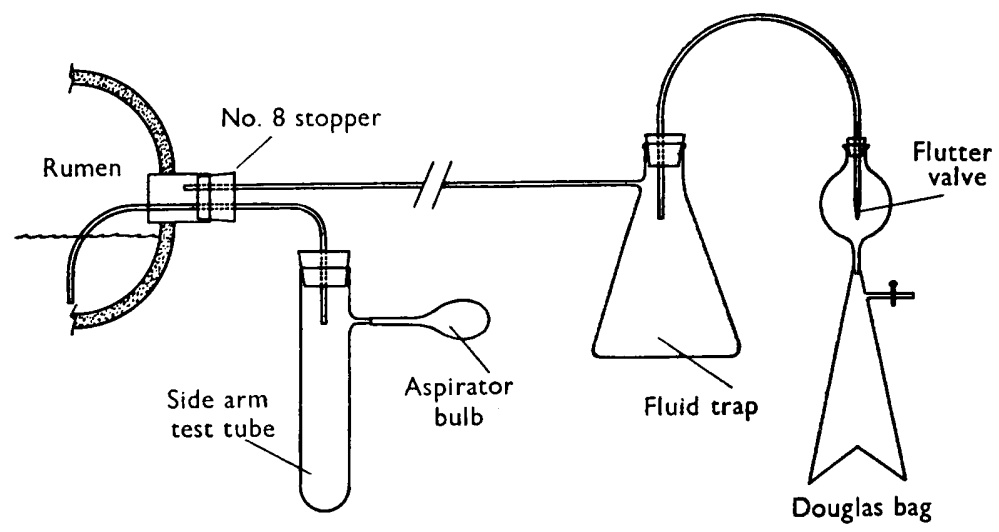

Fig. 2. Schematic representation of apparatus for collection of samples of rumen gas and fluid.

The sodium acetate-2-14 $\mathrm{C}$ was purchased from commercial sources and the sodium acetate- $1-{ }^{14} \mathrm{C}$ was synthesized via carbonation of methyl magnesium iodide in the Radiocarbon Laboratory of the University of Illinois.

Chemical methods. A $50 \mathrm{ml}$. sample of the rumen gas was analysed by absorptioncombustion procedures in a Burrell (Model 35-802) apparatus before fractionation of the remainder of the sample in a gas absorption chain. Carbon dioxide was trapped in a $0.25 \mathrm{~N}$ solution of Primene 81-R (a mixture of tertiary alkyl primary long chain $\mathrm{C}_{12}-\mathrm{C}_{14}$ amines; Rohm \& Hass Co., Philadelphia, Pa.) in methanol (Oppermann, Nystrom, Nelson \& Brown, 1959) contained in a large test tube fitted with a sintered glass gas-diffusion tube. Oxygen was absorbed in the second vessel which contained alkaline pyrogallol prepared by dissolving $15 \mathrm{~g}$. pyrogallic acid and $113 \mathrm{~g}$. potassium hydroxide in $100 \mathrm{ml}$. water. The effluent gas from the absorption train, containing primarily methane and some nitrogen, was subjected to catalytic combustion in the Burrell apparatus.

The carbon dioxide derived from catalytic combustion of methane was absorbed in $0.25 \mathrm{M}$-Primene contained in a special vessel attached to the Burrell apparatus. The gas was passed through the vessel repeatedly until complete absorption had taken place. The volume of carbon dioxide absorbed was recorded and the $\%$ methane present in the original gas sample calculated.

Volatile fatty acids (VFA) present in the rumen were determined by a modification of the chromatographic method of Neish (1949) as described in a previous 


\section{R. A. OppermanN, W. O. Nelson and R. E. Brown}

report by Oppermann et al. (1957). The rumen fluid samples were preserved for analysis by acidification with $10 \mathrm{~N}$-sulphuric acid and were immediately frozen for storage until analysis could be made.

Carbon ${ }^{14} \mathrm{C}$ determinations. When rumen fluid samples were chromatographed, three $1 \mathrm{ml}$. samples were taken, before titration, from three successive $5 \mathrm{ml}$. samples collected from the top of each volatile fatty acid peak and placed in $13 \mathrm{ml}$. of scintillation fluid. The remainder of the eluate was titrated and the amount of fatty acid present calculated on the basis of the original volume. The scintillation fluid was prepared by dissolving $3 \mathrm{~g}$. 2:5-diphenyloxazole (PPO) in a litre of high purity toluene. The fatty acid solutions were counted at $810 \mathrm{~V}$. (tap 3) using discriminator settings of 10-50 V. and 50-100 V. on a Tri-Carb liquid scintillation spectrometer (Model 314X, Packard Instrument Co., LaGrange, Ill.).

The absorbent for all carbon dioxide- ${ }^{14} \mathrm{C}$ samples was either $0.25 \mathrm{M}$ or $\mathrm{M}$-Primene 81-R. Usually $1 \mathrm{ml}$. of absorbent solution containing the trapped carbon dioxide${ }^{14} \mathrm{C}$ was added to $13 \mathrm{ml}$. of scintillation fluid and counted at $890 \mathrm{~V}$. (tap 4) using discriminator settings for 10-50 V. and 50-100 V. in the scintillation counter. Carbon dioxide $-{ }^{14} \mathrm{C}$ was determined at a higher tap number than the fatty acids because of the quenching caused by methanol in the Primene solutions (Oppermann et al. 1959).

Table 1. Distribution of ${ }^{14} \mathrm{C}$ from sodium acetate-2-14C added* to the rumen $18 \mathrm{hr}$. after feeding. Trial 1

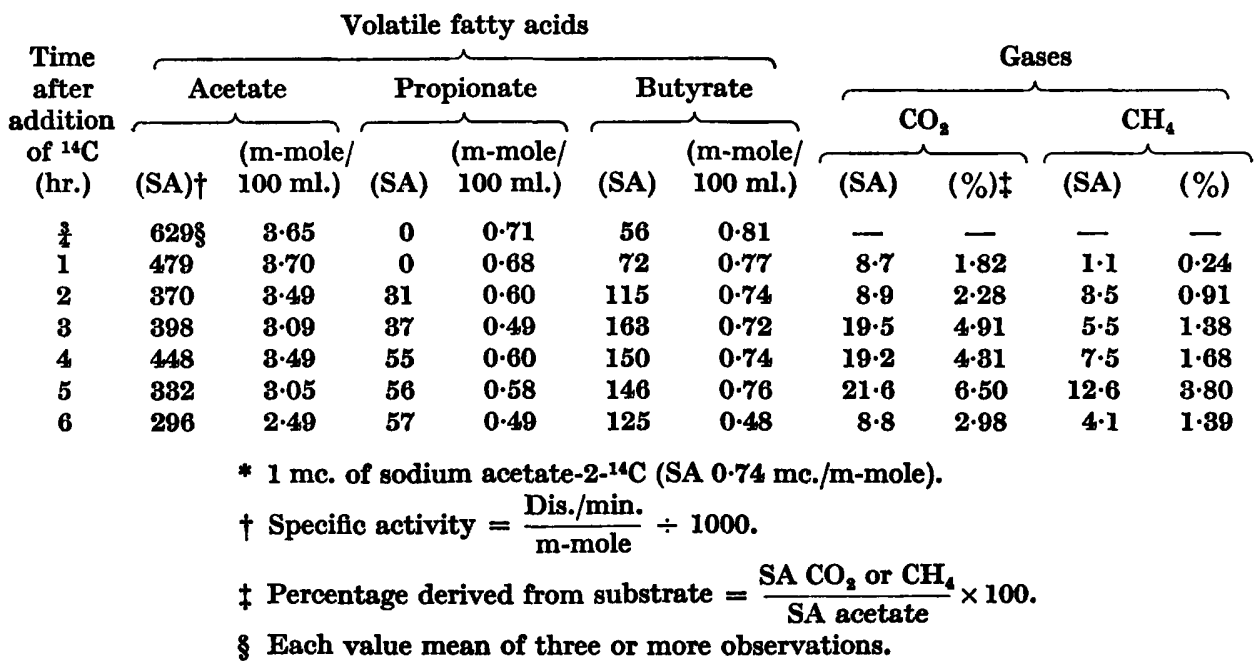

\section{RESULTS}

In the first trial 1 millicurie (mc.) of sodium acetate-2-14 $\mathrm{C}$ having a specific activity (SA) of $0.74 \mathrm{mc}$. $/ \mathrm{mmole}$ was introduced into the rumen $18 \mathrm{hr}$. after feeding, and samples of rumen fluid and gas were collected hourly over a $6 \mathrm{hr}$. period. As shown in Table 1, the methane and carbon dioxide, as well as propionic and butyric acid became labelled soon after the addition of the acetate-2-14 $\mathrm{C}$. The specific activity and the total concentration of the acetate decreased at a moderate rate throughout 
the trial. The amount of ${ }^{14} \mathrm{C}$ in propionic acid increased slightly while the total quantity of this acid decreased slowly. Carbon ${ }^{14} \mathrm{C}$ concentration in butyric acid increased during the first $3 \mathrm{hr}$. and decreased gradually thereafter. The total amount of butyric acid in the rumen fluid remained relatively constant during the first $5 \mathrm{hr}$. before dropping sharply during the sixth hour. The specific activity of the carbon dioxide and methane in the rumen gas increased during most of the experimental period. As the specific activity of each gas gradually increased the $\%$ of the gas derived from acetate also increased.

Although the values of radioactivity encountered in the volatile fatty acids, carbon dioxide, and methane were somewhat lower in the second trial, the data followed the same general pattern. However, as shown in Table 2, radioactivity was not detected in the propionic acid fraction and ${ }^{14} \mathrm{C}$ was detected in butyric acid only in the early median portion of the trial.

Although these experiments show that some of the label from acetate was recovered in vivo in rumen methane, the simultaneous labelling of propionic and butyric acid and carbon dioxide complicated the elucidation of the role of acetate in methane production because the methane ${ }^{14} \mathrm{C}$ could have been derived by reduction of ${ }^{14} \mathrm{CO}_{2}$, or by direct cleavage of the acetate-2-14 $\mathrm{C}$, or both.

The calculation of the relative isotope concentration (Block, Clark \& Harary, 1954) or \% conversion, i.e.:

$$
\frac{\text { specific activity methane- }{ }^{14} \mathrm{C} \text { at } T \text { time }}{\text { specific activity acetate-2- }{ }^{14} \mathrm{C} \text { at } T \text { time }} \times 100=\% \text { conversion, }
$$

shows that maximum values of only 3.8 and $5.6 \%$ of the methane in trials 1 and 2 , respectively, might have been derived from the methyl group of acetate even if it be assumed that labelled butyric acid and/or carbon dioxide- ${ }^{14} \mathrm{C}$ did not participate in the methanogenesis, and that all of the methane- ${ }^{14} \mathrm{C}$ recovered arose from the

Table 2. Distribution of ${ }^{14} \mathrm{C}$ from sodium acetate-2-14 $\mathrm{C}$ added ${ }^{*}$ to the rumen $18 \mathrm{hr}$. after feeding. Trial 2

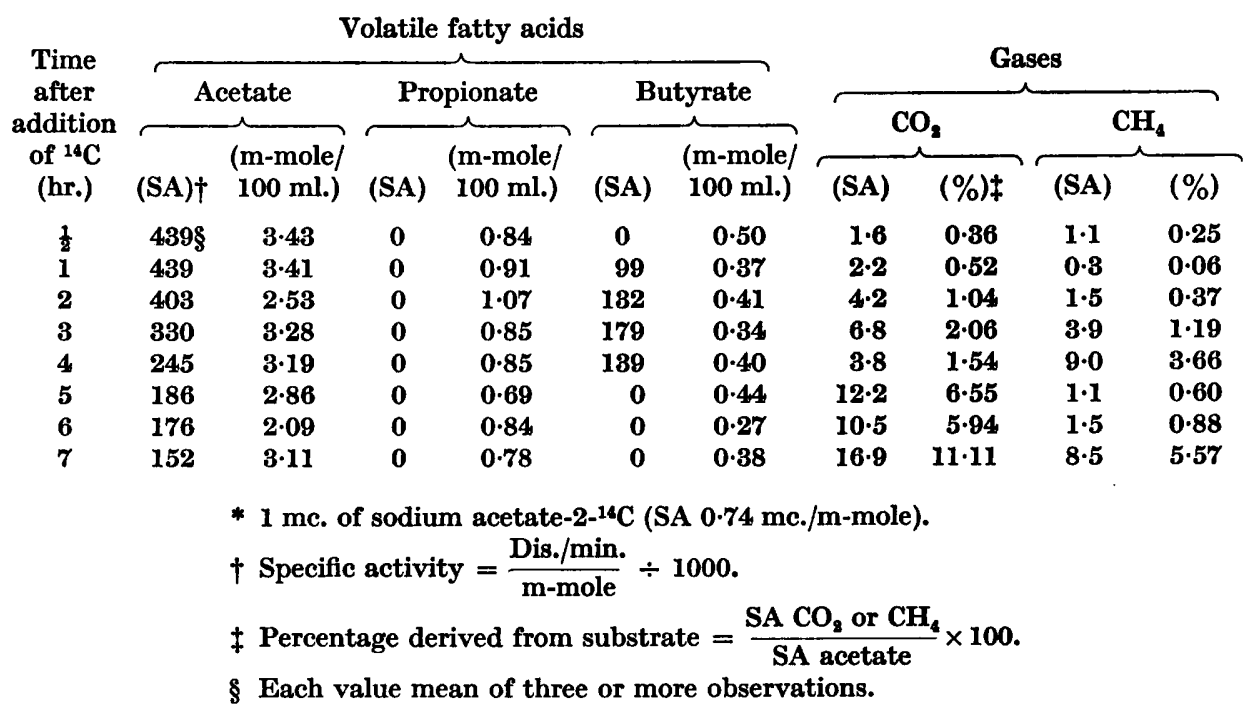




\section{R. A. Oppermann, W. O. Nelson and R. E. Brown}

direct cleavage of acetate, the intact methyl group of this substrate being incorporated into methane in accordance with the findings of Buswell \& Sollo (1948), Stadtman \& Barker (1949) and Pine \& Barker (1956).

Calculation of the relative isotope concentration in acetate as precursor and carbon dioxide as product indicates that acetate participated in reactions which led more readily to the formation of carbon dioxide than to the formation of methane. In trial 1 a maximum of $6.5 \%$ and in trial 2 a maximum of $11 \%$ of the carbon dioxide was derived from the labelled carbon which originally resided in acetate${ }^{2-14} \mathrm{C}$. (Comparable values for methane were 3.8 and $5.6 \%$ for trials 1 and 2 , respectively.)

Whilst the specific activities of carbon dioxide and methane in trial 2 were rather erratic, in general, the relationship of the specific activity curves of carbon dioxide${ }^{14} \mathrm{C}$ and methane- ${ }^{14} \mathrm{C}$ in trials 1 and 2 is that of two products derived from a single precursor. Should there be a decrease in carbon dioxide- ${ }^{14} \mathrm{C}$ in such a manner that its curve crosses that of methane, or an increase in the specific activity of methane so that its curve crosses or touches that of carbon dioxide, then the relationship between the two would be that of precursor (carbon dioxide) to product (methane) (Aranoff, 1956). The point where the specific activity curves cross would be the maximum specific activity of the product. The experimental time period was not extended long enough to determine this final relationship. However, considering the trends of the data, the curves which start as two products probably would end in a new precursor-product relationship.

Table 3 summarizes an experiment in which 1 mc. of acetate-2- ${ }^{14} \mathrm{C}$ (SA $7.5 \mathrm{mc}$./ $\mathrm{m}$-mole) was added to the rumen $30 \mathrm{~min}$. after feeding to determine the effect of maximum rate of rumen fermentation on the incorporation of methyl carbon from acetate into other products of rumen digestion. These data show that the specific activity of acetic acid decreased rapidly during this period as a result of the increased production of acetate in the rumen fermentation. In contrast to the previous trials, the labelling of propionic and butyric acid was more pronounced and the higher volatile fatty acids (greater than $\mathrm{C}_{4}$ ) were labelled throughout the experimental period. The specific activity of butyric acid decreased during the first $2 \mathrm{hr}$., increased during the next $2 \mathrm{hr}$., and then decreased during the remainder of the trial. The concentration of propionic acid-14 $\mathrm{C}$ increased throughout most of the experiment and began to decrease only at the end of the sampling time. The methyl carbon of acetate could account for a maximum of $\mathbf{3 . 2} \%$ of the methane and a maximum of $4.2 \%$ of the carbon dioxide. While the $\%$ of methane derived from the methyl group of acetate was in the general range of values obtained in the previous experiments, the $\%$ of carbon dioxide- ${ }^{14} \mathrm{C}$ was much smaller because of the increased production of carbon dioxide from other sources during this period of maximum activity of the rumen microbiota.

The results from the preceding experiments relative to the contribution of methyl-labelled acetate to rumen methanogenesis and carbon dioxide production suggested an experiment to determine the contribution of the carboxyl group of acetate to the formation of these two gaseous products of rumen digestion. The experimental conditions used were as before except that $2 \mathrm{mc}$. of acetate- $1{ }^{-14} \mathrm{C}$ (SA $2.25 \mathrm{mc} . / \mathrm{m}$-mole) were added to the rumen $18 \mathrm{hr}$. after feeding, as in the first trial. 


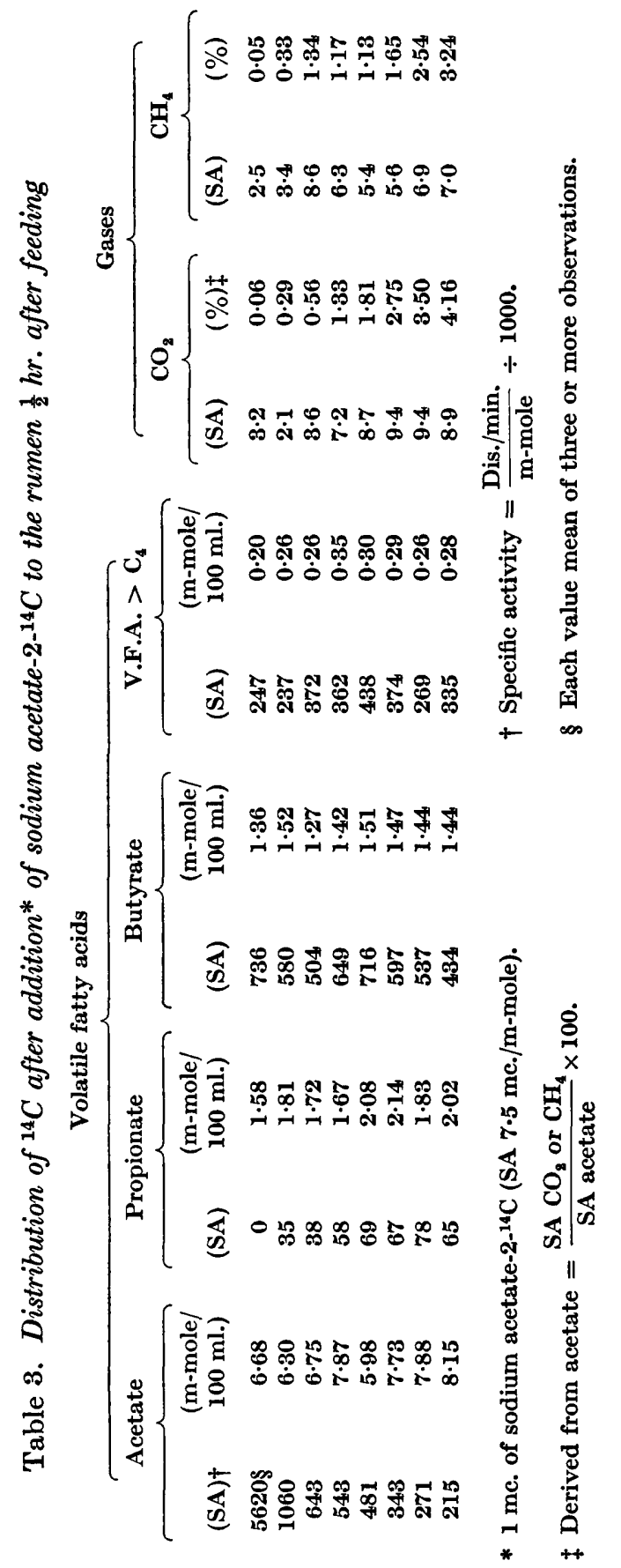

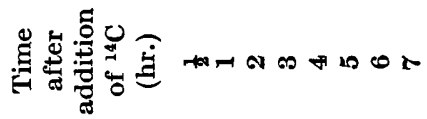

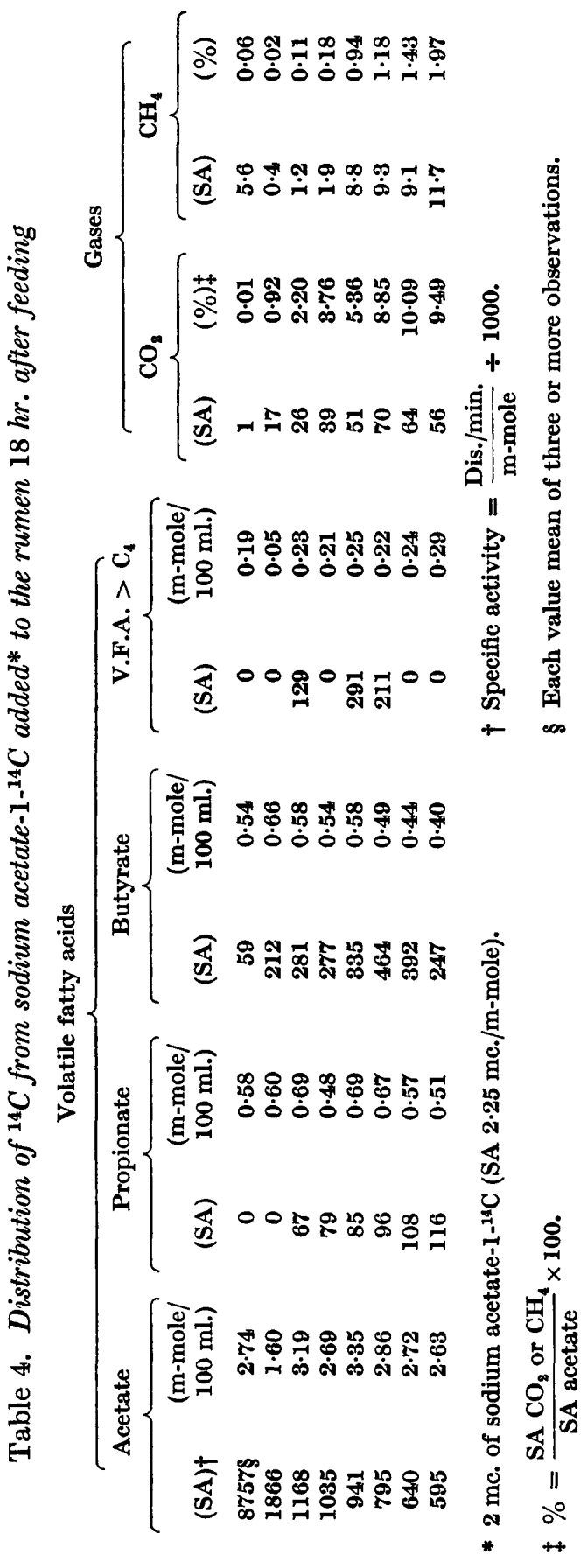

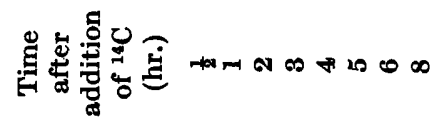


The results (summarized in Table 4) show that the carbon dioxide was much richer in ${ }^{14} \mathrm{C}$ than the methane. The data also show other differences from the preceding experiments, in that the labelling of butyric acid continued for $5 \mathrm{hr}$. instead of $3 \mathrm{hr}$., and the specific activities were higher, even when corrected for the addition of twice as much isotope. The fatty acids with chain lengths greater than $\mathrm{C}_{4}$ also became labelled in some instances. The propionic acid labelling pattern was similar to that of the first experiment. The differences in the labelling of the various volatile fatty acids suggests that the method of incorporation of carboxyl carbon differs from that of the methyl carbon of acetate. It was calculated that the carboxyl group of acetate $-{ }^{14} \mathrm{C}$ gave rise to a maximum of $2 \%$ of the methane and $10 \%$ of the carbon dioxide encountered during the experimental time period.

\section{DISCUSSION}

Although bacteria which convert acetate to methane and carbon dioxide are readily established in enrichment cultures of bovine rumen contents, the data presented in this report demonstrate that only a small portion of rumen methane was derived from acetate and suggest that these organisms were present in small numbers. This observation is in accord with the report (Nelson, Brown \& Kingwill, 1960) that the addition of $d$-limonene to the rumen in vivo in concentrations which were toxic to acetate-utilizing methane bacteria in vitro (Crane, Nelson \& Brown, 1957) did not appreciably alter the ratio $\mathrm{CO}_{2}: \mathrm{CH}_{4}$ in rumen gas. Beijer (1952) previously had observed that methane was not formed from acetate by rumen contents in vitro during short term incubation.

The active participation of acetate- $1-{ }^{14} \mathrm{C}$ and acetate-2- ${ }^{14} \mathrm{C}$ in reactions leading to the labelling of other higher volatile fatty acids in the rumen pool in these experiments is in agreement with the observations of Gray, Pilgrim, Rodda \& Weller (1952) who reported that most of the derived radioactivity was found in the butyrate fraction of rumen fluid after the addition of acetate-1-14C to the rumen of a sheep. The data presented here extend these observations to include the participation of acetate not only in volatile fatty acid synthesis but also in methanogenesis and in the formation of carbon dioxide in the rumen.

The data demonstrating the participation of acetate-2- ${ }^{14} \mathrm{C}$ in reactions leading to the in vivo labelling of other volatile fatty acids and carbon dioxide in the rumen are in direct contrast to the in vitro fermentation of this substrate. When the acetate-2- ${ }^{14} \mathrm{C}$ used in the in vivo trials was fermented in vitro by acetate-stabilized rumen enrichment cultures, essentially all of the radioactivity of the gas resided in the methane and only trace quantities of ${ }^{14} \mathrm{C}$ were found in the carbon dioxide.

It is evident that the participation of acetate in various metabolic reactions in the rumen forestalls any precise measurement of the direct incorporation of the intact methyl group of acetate-2-14C into methane. However, it is possible to ascribe maximum values for this reaction in terms of the experimental values. Calculation of the relative isotope concentration indicates that a maximum of 3.8 and $5.6 \%$ of the methane might have arisen from the intact methyl group. Since the carboxyl carbon of acetate- $1-{ }^{14} \mathrm{C}$ gave rise to $2 \%$ of the methane and $10 \%$ of the carbon dioxide, it can be postulated that the acetate molecule contributed from $\mathbf{5 \cdot 8}$ to $7 \cdot 6 \%$ of the rumen methane and from 16 to $21 \%$ of the carbon dioxide generated 
in the rumen during the fasting experimental period. The contribution of acetate${ }^{2-14} \mathrm{C}$ to carbon dioxide and methane formation during the period of maximum rumen activity immediately after the ingestion of a ration is somewhat less than the above range of values.

\section{REFERENCES}

Aranoff, S. (1956). Techniques in Radiobiochemistry. Ames, Iowa: Iowa State College Press.

BARKer, H. A. (1956). Bacterial Fermentations. New York: John Wiley and Sons, Inc.

BeiJer, W. H. (1952). Methane fermentation in the rumen of cattle. Nature, Lond. 170, 576.

Block, K., Clatrk, L. D. \& Harary, I. (1954). Utilization of branched chain acids in cholesterol synthesis. J. biol. Chem. 211, 687.

Brown, R. E. (1954). Studies on the production of volatile fatty acids in the bovine rumen. Dissertation. University of Maryland.

Busweld, A. M. (1936). Anaerobic fermentations. Bull. Ill. Wat. Surv. no. 32.

Busweli, A. M. \& Sollo, F. W. (1948). The mechanism of the methane fermentation. J. Amer. Chem. Soc. 70, 1778.

Carroll, E. J. \& Hungate, R. E. (1955). Formate dissimilation and methane production in bovine rumen contents. Arch. Biochem. Biophys. 56, 525.

Crane, A., Nelson, W. O. \& Brown, R. E. (1957). Effects of $d$-limonene and $\alpha$ - $d$-pinene on in vitro carbohydrate dissimilation and methane formation by rumen bacteria. J. Dairy Sci. 40, 1317.

Gray, F. V., Pilgrim, A. L., Rodda, H. J. \& Weller, R. A. (1952). Fermentation in the rumen of sheep. IV. The nature and origin of the volatile fatty acids in the rumen of sheep. J. exp. Biol. 29, 57.

KLEIBER, M. (1953). Biosynthesis of milk constituents by intact dairy cow studied with C as tracer. Atomic Energy in Agricultural Research, Oak Ridge, TID 5115, 253.

McNeill, J. J. \& Brown, R. E. (1954). Studies on gaseous products formed in fermentations by bovine rumen bacteria. Maryland Agr. Expt. Sta. Misc. Publ. no. 205, 6.

NeISH, A. C. (1949). Production and properties of 2-3-butanediol. XXX. Determination of fermentation acids by partition chromatography. Canad. J. Res. 27, 6.

Nelson, W. O., Oppermann, R. A. \& Brown, R. E. (1958). In vitro studies on methanogenic rumen bacteria. II. Fermentation of butyric and valeric acid. J. Dairy Sci. 41, 545.

Nelson, W. O., Brown, R. E. \& Kingwill, R. G. (1960). Factors affecting ratios of $\mathrm{CO}_{2}: \mathrm{CH}_{4}$ in bovine rumen gas. J. Dairy Sci. 43, 1654 .

Oppermann, R. A., Nelson, W. O. \& Brown, R. E. (1957). In vitro studies on methanogenic rumen bacteria. J. Dairy Sci. 40, 779 .

Oppermann, R. A., Nystrom, R. F., Nelson, W. O. \& Brown, R. E. (1959). Use of tertiary alkyl primary $\mathrm{C}_{12}-\mathrm{C}_{14}$ amines for assay of $\mathrm{C}^{14} \mathrm{O}_{2}$ by liquid scintillation counting. Int. J. appl. Radiation \& Isotopes, 7, 38.

Pine, M. J. \& Barker, H. A. (1956). Studies on the methane fermentation. XII. The pathway of hydrogen in acetate fermentation. J. Bact. 71, 644 .

Smith, P. H. \& Hungate, R. E. (1958). Isolation and characterization of Methanobacterium ruminantium n.sp. J. Bact. 75, 713.

Stadtman, T. C. \& Barker, H. A. (1949). Studies on the methane fermentation. VII. Tracer experiments on the mechanism of methane formation. Arch. Biochem. 21, 256.

YAHIRo, A. (1959). In vitro studies of formic and acetic acid metabolism by bovine rumen microorganisms. Dissertation Abst. (Kansas State Univ.), 19, 3090. 